[Agr. Biol. Chem., Vol. 25, No. 11. p. 838 843, 1961]

\title{
The Epoxidation of Unsaturated Steroids ${ }^{*}$
}

\author{
By Yuichiro Kurosawa*, Mika Hayano** and Barry M. Bloom*** \\ *Tsurumi Chemical Research Laboratory, Yokohama; \\ **The Worcester Foundation for Experimental Biology, Shrew'sbury, Mass., U.S.A.; \\ *** Medical Research Laboratories, Chas. Pfizer and Co., Inc., Groton, Conn., U.S.A.
}

Received July 24, 1961

\begin{abstract}
Data for several additional instances of epoxidation by biological systems at isolated unsaturated sites on steroid structures are presented.

These systems include the bovine adrenal, Curvularia lunata and a Curvularia species. This reaction predictably occurred only in the presence of enzymes capable of introducing "axial" hydroxyl functions at saturated carbons of corresponding analogous structures. A discussion of the implication of these findings in terms of the mechanism of the enzymatic hydroxylation reaction is given.
\end{abstract}

\section{INTRODUCTION}

In an initial report in 1955, Bloom and Shull ${ }^{1)}$ reported the finding of the stereospecific epoxidation at isolated unsaturated sites in steroids by microorganisms known to effect "axial" hydroxylations at corresponding saturated sites of analogous structures. From the data obtained this type of transformation appeared to encompass a predictable phenomenon. Organisms (Curvularia lunata and Cunninghamella blakesleeana) capable of hydroxylations at C-11 $\beta$ (axial) yielded the C-9 $\beta, 11 \beta$-epoxide from $\Delta^{4,9(11)}$-pregnadiene17a,21-diol-3,20-dione. Similarly, the C-14a, 15a-epoxide was obtained from fermentation of $\Delta^{4,14}$-pregnadiene-17a,21-diol-3,20dione with various fungi (Curvularia lunata, Cunninghamella blakesleeana, Helicostylum piriforme, Mucor griseocyanus and Mucor parasiticus) capable of 14a-hydroxylation. Organisms capable of 11a-hydroxylation (equatorial) and hydroxylations $(6 \beta, 16 a$, etc.) unrelated to the carbons of the unsaturated

* Supported in part by U.S. Public Health Service Grants A-2672.

1) B.M. Bloom and G.M. Shull, J. Am. Chem. Soc., 77, 5767 (1955) . sites on the molecule were unable to form the epoxides. These experiments were extended to the adrenal $11 \beta$-hydroxylating system where a small quantity of the C-9 $\beta, 11 \beta$-epoxide was definitely identified after incubations of $\quad 4^{4,9(11)}$-pregnadiene-17a,21-diol-3,20-dione21-acetate $\left(\Delta^{3(11)}\right.$-Reichstein's Substance $S$ acetate $)^{2}$. In the present paper these data will be presented together with additional examples of epoxidation by microorganisms. The latter includes the transformation of $\left[11,12 a^{3} \mathrm{H}\right]$ $\Delta^{9(11)}$-Reichstein's Substance $S$ acetate into $\left[11,12 a^{-3} \mathrm{H}\right]-\Delta^{4}-9 \beta, 11 \beta$-epoxido-pregnene-17 $a, 21$ diol-3,20-dione by Curvularia lunata (11 $\beta$ hydroxylase) and to $\left[11,12 a^{-3} \mathrm{H}\right]-\Delta^{4}-9 a, 11 \alpha-$ epoxidopregnene-17a,21-diol-3,20-dione by a Curvularia species capable of $9 a$-hydroxylation $^{3)}$. $11 \beta, 12 \beta$-Epoxidoprogesterone was also produced from $\Delta^{11}$-progesterone by Curvularia lunata. No indication of an epoxido product was forthcoming from this substrate fermented with Rhizopus nigricans (11a-hydroxylase).

\footnotetext{
2) B.M. Bloom, M. Hayano, A. Saito, D. Stone and R.I. Dorfman, Fed. Proc., 15, 222 (1956).

3) E.J. Angnello, unpublished data.
} 


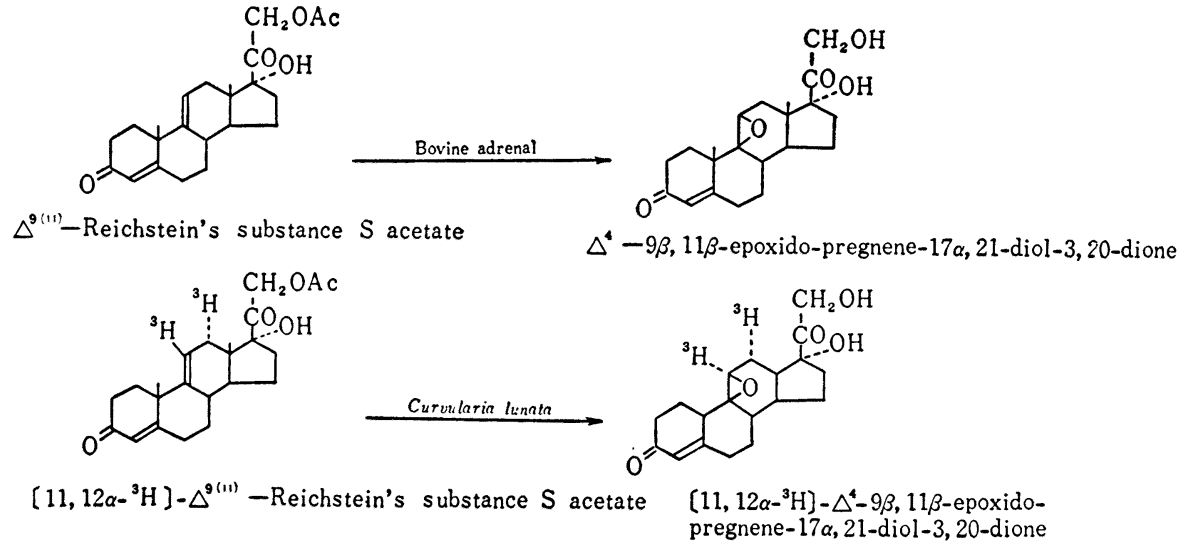<smiles>CC(=O)OCC1(O)CCC2C1=CC1=C3CCC(=O)C=C3CCC12</smiles>

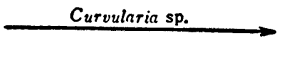<smiles>CCC1CCC2C1C=CC13CCC(=O)C=C1CCC23</smiles>

$\triangle^{11}$-progesterone

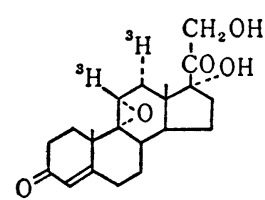

$\left[11,12 \alpha-{ }^{3} \mathrm{H}\right]-\Delta^{4}-9 \alpha, 11 \alpha$-epoxido-pregnene-17 $\alpha$, 21-diol-3,20-dione $\mathrm{CH}_{3}$

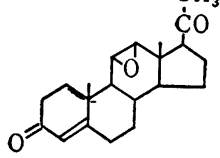

$11 \beta, 12 \beta$-epoxido-progesterone
From the consistent nature of these data have evolved a hypothesis encompassing the gross mechanistic features of oxidative attack on steroidal substrates. Some insight into the enzymatic hydroxylation process has ensued. These ideas in conjunction with other findings from these laboratories, the discovery of the direct incorporation of molecular oxygen ${ }^{4 \sim 7}$ ) in the hydroxy group introduced into steroid structures with over-all retention of configuration $(9,10,11)$ will be discussed in this paper.

4) M. Hayano, M.C. Lindberg. R.I. Dorfman, J.E.H. Hancock and W.V.E. Doering, Arch. Biochem. Biophys., 59, 529 (1955).

5) M. Hayano, N. Saba, R.I. Dorfman and O. Hechter, Recent Progress in Hormone Research, 12, 79 (1956).

6) M. Hayano, A. Saito, D. Stone and P.I. Dorfman, Biochem. Biophys. Acta, 21, 380 (1956)

7) Y. Kurosawa, M. Hayano, M. Gut, R.I. Dorfman, A. Schubert and C.A. Bunton, This Journal, 25, 424 (1961).

\section{EXPERIMENTAL}

(1) Adrenal Incubation of $\mathbf{4}^{9(11)}$-Reichstein's Substance

\section{S Acetate.}

The incubation was essentially conducted as described by Hayano and Dorfman ${ }^{8,9)}$ using a bovine adrenal residue $(5000 \times \mathrm{g})$ preparation. $125 \mathrm{ml}$ Erlenmeyer flasks were shaken at $38^{\circ} \mathrm{C}$ for 2 hours. In a final volume of $565 \mathrm{ml}$, the concentration of additions were as follows: Sodium fumarate, $\mathrm{pH} 7.4,0.04 \mathrm{M}$, magnesium chloride $0.007 \mathrm{M}$, Tris buffer, $\mathrm{pH} \mathrm{7.4,} \mathrm{ATP} 360 \mathrm{mg}$, DPN $360 \mathrm{mg}, 400 \mathrm{mg} \Delta^{9(11)}$-Substance $S$ acetate dissolved in $40 \mathrm{ml}$ of propylene glycol, and bovine adrenal $436 \mathrm{gm}$. The gas phase was air. After the incubation, the material was extracted with ethyl acetate and placed on a silica gel column. Elutions were carried out with benzene, benzene-ethyl acetate mixtures with

8) M. Hayano and R.I. Dorfman, J. Biol. Chem., 201, 175 (1953).

9) M. Hayano and R.I. Dorfman, ibid., 211, 227 (1954). 
increasing polarities, acetone and then methanol. All steroids were eluted in the aceton fraction. This fraction was acetylated and approximately $250 \sim 300 \mathrm{mg}$ of crystalline $\Delta^{\vartheta(11)}$-Substance $S$ acetate separated directly. Paper chromatography of the mother liquors revealed the presence of five zones: 1) material with polarity equivalent to hydrocortisone acetate, 2) $9_{\beta}, 11_{\beta}$-oxido-Substance $\mathrm{S}$ acetate, 3) material with polarity equivalent to corticosterone acetate, 4) residual $\Delta^{9(11)}$-Substance $S$ acetate, and 5) a less polar bluetetrazolium reducing zone. The epoxide zone was eluted with chloroform and rechromatographed in a (1:1) benzene-cyclohexane formamide system. Again the epoxide zone was eluted with chloroform. Evaporation of the solvent gave a residue too small to warrant crystallization or infrared analysis. The sulfuric acid chromogen of this material, a criterion selected as most revealing, was carried out and compared with that of authentic $9 \beta, 11 \beta$-epoxido-Substance $S$ acetate. The two patterns proved identical in every respect. The chromogen is sufficiently characteristic to eliminate any possibility of confusion with those of the several endogenous corticosteroids. Approximately $4 \sim 12 \mathrm{mg}$ of epoxide was formed from $400 \mathrm{mg}$ of substrate or a conversion yield of $1 \sim 3 \%$.

Tissue Blanks:

218 grams of bovine adrenal tissue without steroid addition were processed identically as described above. $1.986 \mathrm{gm}$ of syrup were obtained in the acetone fraction. No materials resembling steroid epoxide were recognized.

(2) Fermentation of $\left[11,12 \alpha x^{3} \mathrm{H}\right]-\Delta^{9(11)}-$ Substance $\mathrm{S}$ Acetate with Curvularia lunata.

$500 \mathrm{mg}$ of $\left[11,12 a^{-3} \mathrm{H}\right]-\Delta^{9(11)}$-Substance $\mathrm{S}$ acetate was fermented with Curvularia lunata, an organism capable of $11 \beta$-hydroxylation as described by Hanson et al. ${ }^{10)}$ After removal of the mycelium by filtration, the medium was extracted with ethyl acetate, and the extracts concentrated to dryness. The oily residue thus obtained was subjected to chromatography on a silica gel column using as eluates varying proportions of ethyl acetate in benzene. $\left[11,12 \alpha^{-}{ }^{3} \mathrm{H}\right]-\Delta^{\theta(11)}-$ Substance $S$ was eluted with a 2:1 mixture and recrystallized from acetone-ether to yield material, m.p. 227 $9{ }^{\circ} \mathrm{C} . \quad\left[11,12 \alpha^{-3} \mathrm{H}\right]-\Delta^{4} \cdot 9 \beta, 11 \beta$-Epoxido-pregnene-17 $\alpha, 21$. diol-3,20-dione was eluted with a 1:1 mixture and

10) F.R. Hanson, K.M. Mann, E.D. Nielson, H.V. Anderson, M.P. Brunner, J.N. Karnemaat, D.R. Colingsworth and W.J. Haines, J. $A m$. Chem. Soc., 75, 5369 (1953). recrystallized from acetone-ether, m.p. $208 \sim 11^{\circ} \mathrm{C} \quad(54$ $\mathrm{mg})$. Infrared analysis and comparison against known standards established the identities of these crystals. The radioactivity in these compounds were determined in a Packard Tri-Carb liquid scintillation counter Model 314. Accuracy $\pm 3 \%$. All melting points were obseved on a Fisher-Johns hot stage, and are uncorrected. The results showed that there was no loss of the radioactivity of the substrate in the course of the bio-epoxidation.

Counts $/ \mathrm{min} / \mathrm{micromol}$

Recovered substrate :

$$
\begin{array}{r}
{\left[11,12 \alpha-^{-8} \mathrm{H}\right]-\Delta^{9(11)}-\text { Substance } \mathrm{S}} \\
\text { m.p. } 227 \sim 9^{\circ} \mathrm{C}
\end{array}
$$

Isolated product :

$$
\left[11,12 \alpha-{ }^{8} \mathrm{H}\right]-\Delta^{4}-9 \beta, 11 \beta-\text { Epoxido- }
$$$$
\text { pregnene-17 } \alpha, 21 \text {-diol-3,20-dione }
$$

m.p. $208 \sim 11^{\circ} \mathrm{C}$

(3) Fermentation of $\left[11,12 \alpha^{-3} \mathbf{H}\right]-\Delta^{9(11)}$-Substance $\mathbf{S}$ Acetate with Curvularia sp.

$475 \mathrm{mg}$ of $\left[11,12 \alpha^{-3} \mathrm{H}\right]-\Delta^{9(11)}$-Substance $\mathrm{S}$ acetate was fermented with Curvularia sp., an organism capable of $9 a$-hydroxylation. In the silica gel chromatography of fermented extracts $\left[11,12 a^{-3} \mathrm{H}\right]-\Delta^{9(11)}$-Substance $S$ acetate was eluted with a $6: 1$ benezne-ethyl acetate mixture and recrystalized from acetone-ether to give material, m.p. $233 \sim 6^{\circ} \mathrm{C}(42 \mathrm{mg}) \cdot\left[11,12 \alpha^{-3} \mathrm{H}\right] \cdot \Delta^{9(11)}$ Substance $S$ was eluted with a 3:1 mixture and recrystallized from acetone-ether, m.p. $227^{\circ} \mathrm{C}$. The conversion product, $\left[11,12 \alpha^{-3} \mathrm{H}\right]-\Delta^{4}-9 a, 11 \alpha$-epoxido-pregnene-17a,21-diol-3,20-dione was eluted with a $2: 1 \mathrm{mix}$ ture and recrystallized from acetone-ether to yield product, m.p. $223^{\circ} \mathrm{C}(204 \mathrm{mg})$. All crystals were identified by infra-red analysis and comparison against standards. The radioactivity content was as follows: These results also showed that the radioactivity at C-11 remained intact in the course of bio-epoxidation.

Counts $/ \mathrm{min} / \mathrm{micromol}$

Recovered substrate :

$$
\begin{aligned}
& {\left[11,12 \alpha-{ }^{8} \mathrm{H}\right]-\Delta^{9(11)} \text {-Substance } \mathrm{S}} \\
& \text { acetate }
\end{aligned}
$$

$$
\text { m.p. } 233 \sim 6^{\circ} \mathrm{C}
$$

Isolated product :

$$
\left[11,12 \alpha^{-8} \mathrm{H}\right]-\Delta^{4}-9 \alpha, 11 \alpha-\text { Epoxido- }
$$
pregnene-17 $\alpha, 21$-diol-3,20-dione 
(4) Fermentation of $\Delta^{11}$-progesterone with Curvularia lunata and Rhizopus nigricans.

$25 \mathrm{mg}$ portions of $\Delta^{11}$-progesterone was fermented with Curvularia lunata, an organism capable of $11 \beta$ hydroxylation, and Rhizopus nigricans, an organism capable of 11 a-hydroxylation. After the fermentation the filtrate was extracted with ethyl acetate. The resulting residue was subjected to paper chromatography, using the ligroin-propylene glycol system ${ }^{11)}$. A reagent employed in the detection of steroids was the isonicotinic acid hydrazide solution for the $\Delta^{\mathbf{4}-3-}$ keto grouping ${ }^{12)}$ (yellow color and fluorescence under long ultra-violet). The starting material, $\Delta^{11}$-progesterone, was contained in a zone with $\mathrm{Rlig}$. of approximately $5.0 \sim 6.0 \mathrm{~cm} / \mathrm{hr}$. The more polar region was eluted with ethyl acetate. $9.3 \mathrm{mg}$ of oily residue was obtained from the C. lunata fermentation and $15.8 \mathrm{mg}$ of oily residue from $R$. nigricans. These residues were subjected to silica gel column chromatography. From C. lunata, $200 \sim 300 \gamma$ of crystalline $11 \beta, 12 \beta$ epoxido-progesterone was eluted with a $2: 1$ benzeneethyl acetate mixture and identified by IR analysis through comparison with a standard generously pro- vided by Dr. J. Fried of Squibb, Sharp \& Dohme Co. No epoxido-product was demonstrated from the $R$. nigricans fermentation.

(5) Prepration of $\left[11,12 \alpha^{-3} \mathrm{H}\right]-\Delta^{9(11)}$ Substance S Acetate.

$270 \mathrm{mg}$ of $\Delta^{11}$-pregnene-3,20-dione in $15 \mathrm{ml}$ ethyl acetate was shaken in a closed bulb overnight at room temperature with $110 \mathrm{mg}$ of $30 \%$ prereduced $\mathrm{Pd}$ on C under two atmospheres of $1: 40$ by volume of tritium in hydrogen. $\left[11_{a}, 12 \alpha^{-}{ }^{3} \mathrm{H}\right]$-Pregnane-3,20-dione thus prepared was filtered, crystallized from acetone to yield material, m.p. $120^{\circ} \mathrm{C}$, and found to contain about $7.5 \times 10^{8} \mathrm{cpm} / \mathrm{mg}$. Approximately $10 \mathrm{mg}$ of this substance were diluted with $300 \mathrm{mg}$ of carrier pregnanedione for conversion to progesterone. Bromination in dimethyl formamide and dehalogenation with $\mathrm{LiCl}$ were carried out according to the method of Holysz ${ }^{13}$. Purification of progesterone was achieved with silica gel chromatography using benzene-ethyl acetate mixtures. Progesterone was eluted with a $7: 1$ combination. $190 \mathrm{mg}$ of pure crystals, m.p. $127 \sim 9^{\circ} \mathrm{C}$, were diluted with $100 \mathrm{mg}$ of carrier and perfused through bovine adrenals ${ }^{14)}$ and extracted according to a proce-

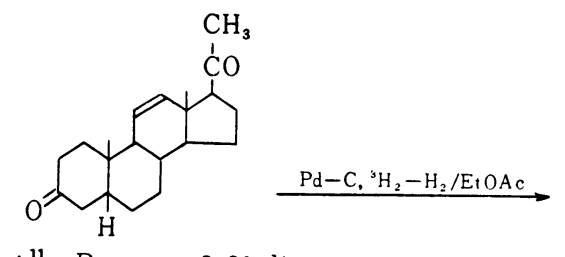

$\triangle^{11}-$ Pregnene-3, 20-dione
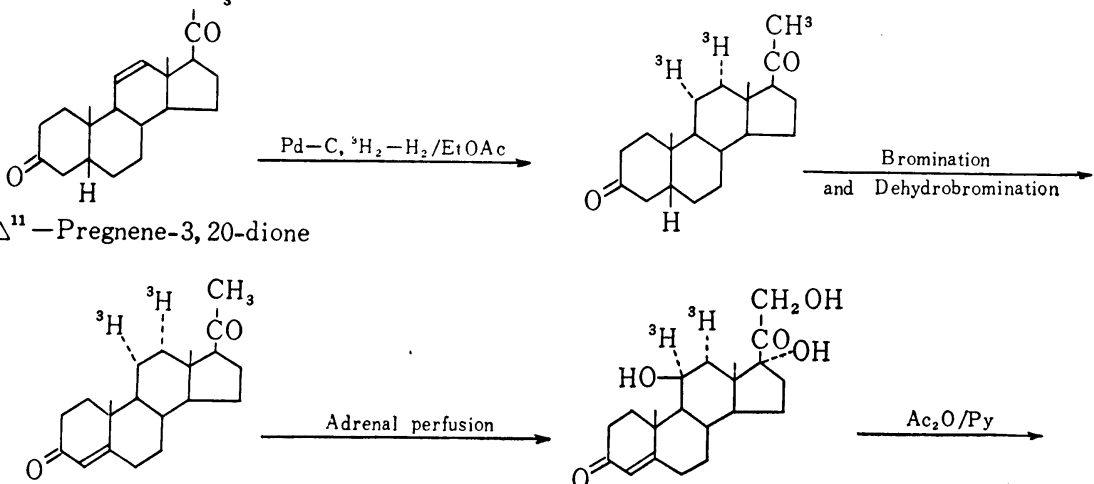

$\left[11 \alpha, 12 \alpha-{ }^{3} \mathrm{H}\right]-$ Progesterone
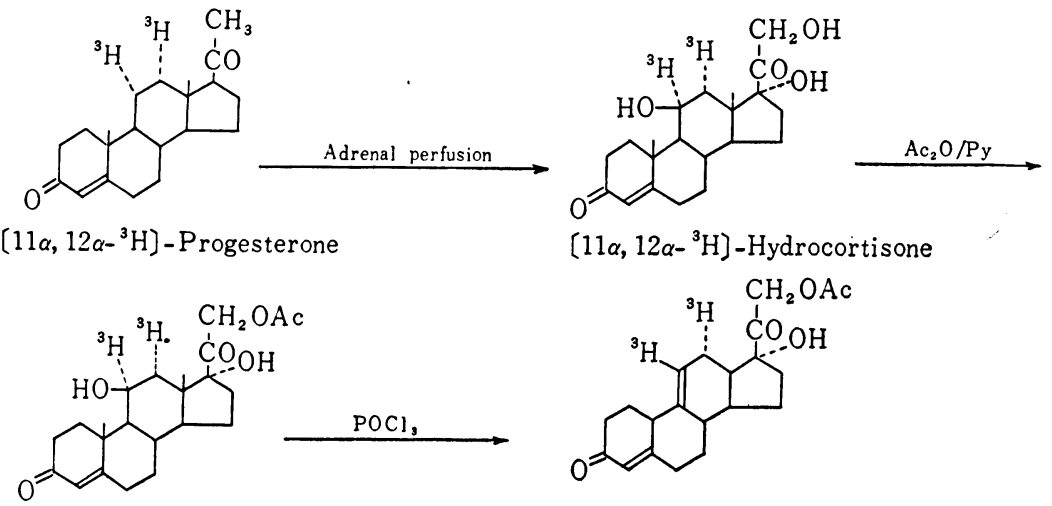

$\left[11 \alpha, 12 \alpha-{ }^{3} \mathrm{H}\right]$-Hydrocortisone

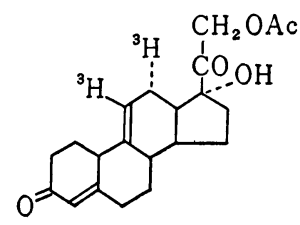

$\left[11,12 \alpha-{ }^{3} \mathrm{H}\right]-\Delta^{9(11)}$ Substance $S$ acetate

13) R.P. Holysz, J. Am. Chem. Soc., 75, 4432 (1953).

14) O. Hechter, A. Zaffaroni, R.P. Jacobson, H. Levy, R.W.

11) C. Savard, J. Biol. Chem., 202, 457 (1953).

12) L.L Smith and T. Foell, Analytical Chemistry, 31, 102 (1959). Jeanloz, V. Schenker and G. Pincus, Recent Prog. Hormone Research, 6, 215 (1951). 
dure modified by Levy ${ }^{15)}$ using isopropyl acetate. The crude material thus obtained was resolved by silica gel chromatography using benzene-ethyl acetate mixture. Hydrocortisone was obtained in the ethyl acetate eluate and counted about $19 \times 10^{8} \mathrm{cpm} / \mathrm{mg}$. About $5 \mathrm{mg}$ of the ${ }^{3} \mathrm{H}$-hydrocortisone were diluted with $130 \mathrm{mg}$ of carrier and acetylated. The acetate was treated with $\mathrm{POCl}_{3}$ according to the method of Graber et al.16) in the presence of $100 \mathrm{mg}$ of $\Delta^{9(11)}$-Substance $S$ acetate, and purified by silica gel chromatography. $\Delta^{9(11)}$. Substance $S$ acetate was eluted with $4: 1$ benzene-ethyl acetate, and yielded crystals, m.p. $239^{\circ} \mathrm{C} .82 \mathrm{mg}$ of this substance was diluted with $507 \mathrm{mg}$ of carrier to give a count of about $10,000 \mathrm{cpm} / \mathrm{mg}$. This material was used in the fermentation with Curvularia lunata for $9 \beta, 11 \beta$-epoxidation. A second batch of $4^{9(11)}$-Substance $S$ acetate was prepared as described above for use with Curvularia sp. (9a,11 a-epoxidation). This material counted about $25,000 \mathrm{cpm} / \mathrm{mg}$.

\section{DISCUSSION}

The experimental observations presented above and previously documented ${ }^{1)}$ can be summarized as follows: An enzyme capable of introducing a hydroxyl function axial at a specific carbon of a saturated steroid can also effect the introduction of an epoxide grouping "axial" at that same carbon in the corresponding unsaturated substrate. Equatorial hydroxylases did not effect similar conversions. It is hypothesized that epoxidation of olefinic steroids may occur because of the spatial resemblance of double bond $\pi$-electron distribution in a given unsaturated substrate to the area of maximum electron density in the related axial carbon-hydrogen bond of the corresponding saturated compound. That is, in the appropriate enzyme-substrate complex the spatial relationship required for reaction between an "axial"-hydroxylase and an axial carbon-hydrogen bond in the case of a saturated steroid is adequately approximated by the "axial"-hydroxylase- $\pi$-electron relationship in the unsaturated analog. It follows that a

\footnotetext{
15) H. Levy, unpublished data.

16) R.P. Graber, A.C. Haven, JR., and N.L. Wendoler, J. Am. Chem. Soc., 75, 4722 (1953).
}

reasonable degree of structural specificity in the oxidizing enzyme system would preclude occurrence of the epoxidation phenomenon with "equatorial"-hydroxylase, since equatorial bonds extend outward more in the plane of the cyclohexane ring to which they are attached, while in the corresponding cyclohexene system maximum of $\pi$-electron density would occur directly above and below the plane of the trigonal carbons and their substituents, with minimum electron density in the plane.

Inherent in this hypothesis is the assumption that hydroxylation proceed by direct electrophilic attack. Such evidence is now available in the demonstrations of enzymatic hydroxylations at $7 a^{17)}, 11 a^{18)}$ and $11 \beta^{19)}$ of $\mathrm{C}_{21}$-steroids where the incoming hydroxyl function replaced the hydrogen at those positions hydroxylated with retention of configuration. In chemical systems electrophilic displacement at saturated carbon atoms have also been found to occur in this way ${ }^{20)}$.

\section{SUMMARY}

Four instances of the epoxidation of steroids by biological preparations of known "axial" hydroxylating capacity have been demonstrated.

(1) $\Delta^{4}-9 \beta, 11 \beta$-Epoxido-pregnene-17-a-21-diol3,20-dione was observed after incubation of $\Delta^{9(11)}$-Substance $S$ acetate with bovine adrenal $11 \beta$-hydroxylase.

(2) $\left[11,12 a^{3} \mathrm{H}\right]-\Delta^{4}-9 \beta, 11 \beta$-Epoxido-pregnene17a,21-diol-3,20-dione was isolated from the culture broth of $\left[11,12 a^{-3} \mathrm{H}\right]-\Delta^{9(11)}$-Substance $\mathrm{S}$ acetate fermented with Curvularia lunata.

(3) $\left[11,12 \alpha^{-3} \mathrm{H}\right]-\Delta^{4}-9 a, 11 \alpha$-Epoxido-pregnene-

17) S. Bergstrom, S. Lindstredt, B. Samuelson, E.J. Corey and G.A. Gregoriou, J. Am. Chem. Soc., 80, 2337 (1958).

18) E.J. Corey, G.A. Gregoriou and D.H. Peterson, ibid., 80, 2338 (1958) .

19) M. Hayano, M. Gut, R.I. Dorfman, O.K. Sebek and D.H. Peterson, J. Chem. Soc., 80, 2336 (1958).

20) E.J. Corey and G.A. Gregoriou, J. Am. Chem. Soc., 81, 3127 (1959) . 
17a,21-diol-3,20-dione was isolated from the culture broth $\left[11,12 a^{-3} \mathrm{H}\right]-\Delta^{9(11)}$-Substance $\mathrm{S}$ acetate fermented with Curvularia sp. capable of $9 a$-hydroxylation.

(4) $11 \beta, 12 \beta$-Epoxido-progesterone was isolated from the culture broth of $\Delta^{11}$-progesterone fermented with Curvularia lunata.
A discussion is presented to relate corresponding epoxidations and hydroxylations in terms of molecular spatial relationships. An extension to the question of the electrophilic nature of the hydroxylating species is included. 